\title{
Stiff-Chain Nature of Poly(1-phenyl-1-propyne) in Dilute Solution
}

\author{
Takayuki Hirao, Akio Teramoto, Takahiro Sato, Takashi NorisuYe, \\ Toshio Masuda, ${ }^{*}$ and Toshinobu Higashimura* \\ Department of Macromolecular Science, Osaka University, \\ Toyonaka, Osaka 560, Japan \\ * Department of Polymer Chemistry, Kyoto University, Kyoto 606, Japan
}

(Received November 19, 1990)

\begin{abstract}
Light scattering and viscosity measurements were made on twelve narrowmolecular weight distribution samples of poly(1-phenyl-1-propyne) in toluene and in cyclohexane. In cyclohexane at $36^{\circ} \mathrm{C}$, the second virial coefficient $\mathrm{A}_{2}$ vanished, the mean-square radius of gyration increased linearly with weight-average molecular weight $M_{w}$, but the intrinsic viscosity was not proportional to $M_{w}^{1 / 2}$. Thus poly(1-phenyl-1-propyne) in cyclohexane at $36^{\circ} \mathrm{C}$ is an unperturbed semiflexible polymer. $\mathrm{A}_{2}$ in toluene was positive, indicating significant intermolecular excluded volume effect. However the intramolecular excluded volume effect became appreciable only at $M_{w}$ higher than $3 \times 10^{5}$. Analysis of the light scattering and viscosity data in terms of the wormlike chain model gave persistence lengths of 3.8 and $3.9 \mathrm{~nm}$ in cyclohexane and toluene, respectively. The Flory viscosity factor in the unperturbed-coil limit was $2.17 \times 10^{23}$ and $2.35 \times 10^{23} \mathrm{~mol}^{-1}$ in the two solvents.

KEY WORDS Semiflexible Polymer / Wormlike Chain / Persistence Length / Stiffness / Flory Viscosity Factor / Excluded Volume Effect / Poly(1phenyl-1-propyne) / Substituted Polyacetylene /
\end{abstract}

Masuda and Higashimura ${ }^{1,2}$ have succeeded in polymerizing substituted acetylenes to yield high molecular weight polymers with alternating double bonds along the main chain. Unlike polyacetylene which has virtually no solvent, these substituted polyacetylenes are soluble in ordinary organic solvents and stable in the solid state, thus permitting molecular characterization. Masuda et al. ${ }^{2,3}$ found for some substituted polyacetylenes that the viscosity exponent in the Mark-Houwink-Sakurada relation was as large as 1 , suggesting that those polyacetylenes would be stiff-chain polymers. They attributed this stiffness to the alternating double bonds on the main chain and bulky side chains attached to it. Therefore, as a continuation of studies on dilute solution properties of stiff polymers, ${ }^{4-13}$ we have chosen one of such polymers, poly(1-phenyl- 1-propyne) (PPP) with the chemical structure shown in Figure 1 and made light scattering, sedimentation equilibrium, and viscosity measurements. This polymer dissolves in toluene (good solvent) and in cyclohexane (poor solvent) and has no absorption for visible light. $^{2,3}$ It seemed interesting to compare its solution behavior with that of polystyrene because of the similarity in chemical structure and solvent between the two polymers. Indeed we found that PPP is brought to the unperturbed state in cyclohexane at $36^{\circ} \mathrm{C}$ but behaves as a semiflexible polymer.

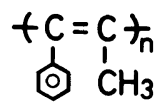

Figure 1. Repeating unit of poly(1-phenyl-1-propyne) (PPP). 


\section{EXPERIMENTAL}

Four samples of PPP with different molecular weights were synthesized as described before. $^{3}$ They were separated into many fractions by repeated precipitation fractionation in benzene-methanol mixtures containing 4,4 thiobis-(6-tert-butyl- $m$-cresol), an antioxidant. Appropriate twelve fractions designated A-1 through A-12 were chosen for physical measurements. Just before solution preparation, they were freed from the antioxidant by reprecipitating the polymer from benzene solutions into methanol and freezedried from benzene solutions.

Light scattering measurements' on eight fractions A-1 through A-8 in toluene at $25^{\circ} \mathrm{C}$ and in cyclohexane at temperatures between 30 and $45^{\circ} \mathrm{C}$ were performed on a Fica 50 light scattering photometer with vertically polarized incident light of the $436-\mathrm{nm}$ or $546-\mathrm{nm}$ wavelength following the procedure established. ${ }^{8}$ Data were analyzed by the square-root plot to obtain weight-average molecular weights $M_{w}$, second virial coefficients $A_{2}$, and $z$-average mean-square radii of gyration $\left\langle S^{2}\right\rangle_{z}$.

Both cyclohexane and toluene solutions of fractions A-6, A-7, and A-8 exhibited optical anisotropy, so that the optical anisotropy factor $\delta$ was estimated for these fractions using the relation ${ }^{14,15}$

$$
\lim _{c \rightarrow 0, \theta \rightarrow 0}\left(R_{\theta, H_{\mathrm{v}}} / K c\right)=3 \delta M_{w}
$$

Here, $R_{\theta, H_{\mathrm{v}}}$ is the reduced scattering intensity measured at a scattering angle $\theta$ for vertically polarized incident light with the analyzer set in the horizontal direction, $K$ the optical constant, and $c$ the polymer mass concentration. The light scattering data for the three fractions were corrected for the anisotropy effect by the conventional method for Gaussian chains ${ }^{14}$ (see Discussion) to obtain $M_{w}, A_{2}$, and $\left\langle S^{2}\right\rangle_{z}$, though the correction was no more than $2 \%$ for $M_{w}$ and $\left\langle S^{2}\right\rangle_{z}$ and $4 \%$ for $A_{2}$.

Specific refractive index increments at infinite dilution $(\partial n / \partial c)_{0}$ were measured on a modified Schulz-Cantow type differential refractometer for solutions of PPP in toluene at $25^{\circ} \mathrm{C}$ and in cyclohexane at temperatures $T\left({ }^{\circ} \mathrm{C}\right)$ between 30 and $45^{\circ} \mathrm{C}$. The values of $(\partial n / \partial c)_{0}$ in toluene were $0.1861 \mathrm{~cm}^{3} \mathrm{~g}^{-1}$ at $436 \mathrm{~nm}$ and $0.1656 \mathrm{~cm}^{3} \mathrm{~g}^{-1}$ at $546 \mathrm{~nm}$. The values in cyclohexane were determined to be

$$
\begin{aligned}
(\partial n / \partial c)_{0}= & {\left[0.264+5.3 \times 10^{-4}(T-30)\right] } \\
& \mathrm{cm}^{3} \mathrm{~g}^{-1} \\
(\partial n / \partial c)_{0}= & {\left[0.234+4.7 \times 10^{-4}(T-30)\right] } \\
& \mathrm{cm}^{3} \mathrm{~g}^{-1}
\end{aligned}
$$

Sedimentation equilibrium measurements were made for toluene solutions of fractions A-8 through A-12 at $25^{\circ} \mathrm{C}$ on a BeckmanSpinco model E analytical ultracentrifuge. The partial specific volume of PPP in toluene at $25^{\circ} \mathrm{C}$ needed to analyze the data was measured to be $0.863 \mathrm{~cm}^{3} \mathrm{~g}^{-1}$. Intrinsic viscosities $[\eta]$ were determined by using a four-bulb capillary viscometer or an ordinary capillary viscometer of the Ubbelohde type.

Although PPP was stable in the solid state, its stability in solution was questioned because of its alternating double bonds on the main chain. Therefore viscosity measurements on cyclohexane and toluene solutions were made in order to find a condition whereby possible degradation of the polymer could be avoided; $\left(\ln \eta_{\mathrm{r}}\right) / c$ was taken as a measure of molecular weight, with $\eta_{\mathrm{r}}$ being the relative viscosity of the solution. It was found that in both toluene and cyclohexane $\left(\ln \eta_{\mathrm{r}}\right) / c$ decreased at a rate of $0.2 \% / \mathrm{h}$ for a high molecular weight sample A-2 but at a negligible rate for a lower molecular weight sample (viscosity-average molecular weight $=8 \times 10^{4}$ ). This shows that higher molecular weight PPP degrades gradually in toluene and in cyclohexane. To minimize effects of degradation on measured properties, all the manipulations from solution preparation to measurement were completed within $12 \mathrm{~h}$, except for sedimentation equilibrium measurements. It took one to two days to complete the 
sedimentation experiment. However this experiment was done only for samples with molecular weights lower than $8 \times 10^{4}$.

\section{RESULTS}

Figure 2 shows representative Zimm plots in the square-root form for A-3 in cyclohexane at $36^{\circ} \mathrm{C}$ and $\mathrm{A}-4$ in toluene at $25^{\circ} \mathrm{C}$. Sedimentation equilibrium data for fractions A-8 through A-12 were used to estimate $M_{w}$, $M_{z}$ (the $z$-average molecular weight), and $A_{2}$. As seen in Table I summarizing the light
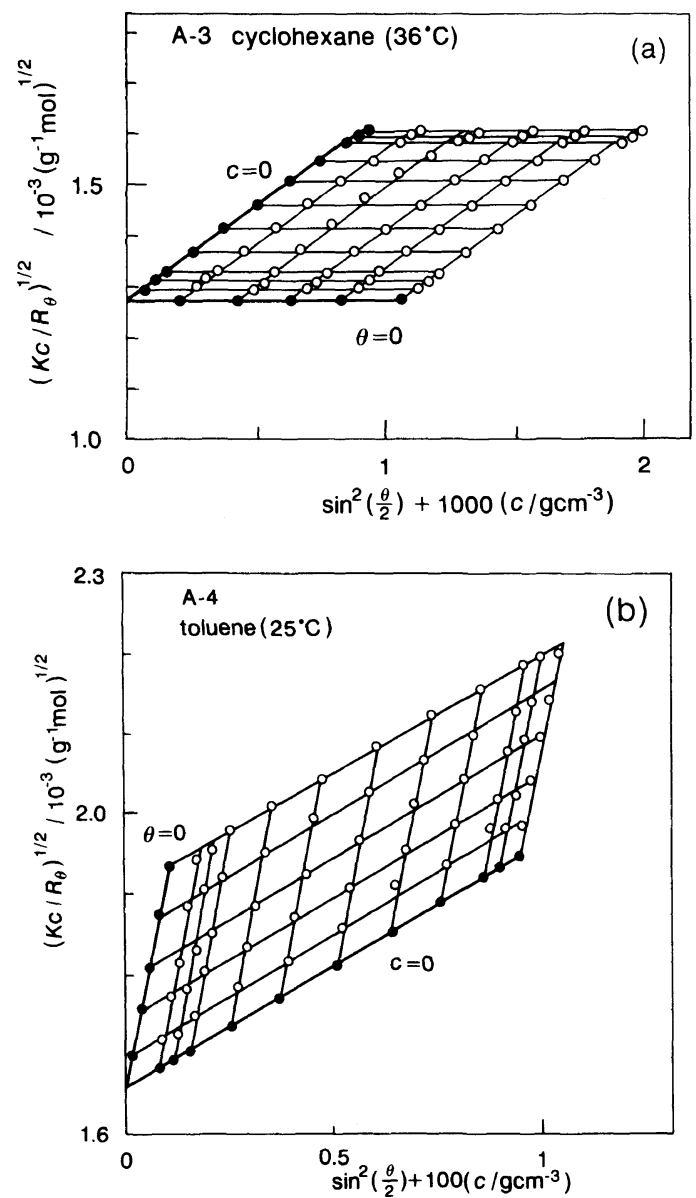

Figure 2. Zimm plots in the square-root form for PPP (a) sample A-3 in cyclohexane at $36^{\circ} \mathrm{C}$, (b) sample A-4 ir toluene at $25^{\circ} \mathrm{C} ; R_{\theta}$ is the reduced scattering intensity measured at a scattering angle $\theta$ with a vertically orientec polarizer and no analyzer. scattering and sedimentation data, these samples are essentially monodisperse, with the polydispersity index $M_{z} / M_{w}$ being $1.06-1.09$. The values of $M_{w}$ for fractions A-1 through A-8 in the different solvents are seen to agree with each other within $5 \%$ and those for fraction A-8 from different experiments, within $2 \%$.

Figure 3 shows the temperature dependence of $A_{2} M_{w}$ for three fractions A-3 through A-5 in cyclohexane. For any of these fractions, $A_{2}$ is negative at lower temperatures, positive at higher temperatures, and vanishes at $36^{\circ} \mathrm{C}$.

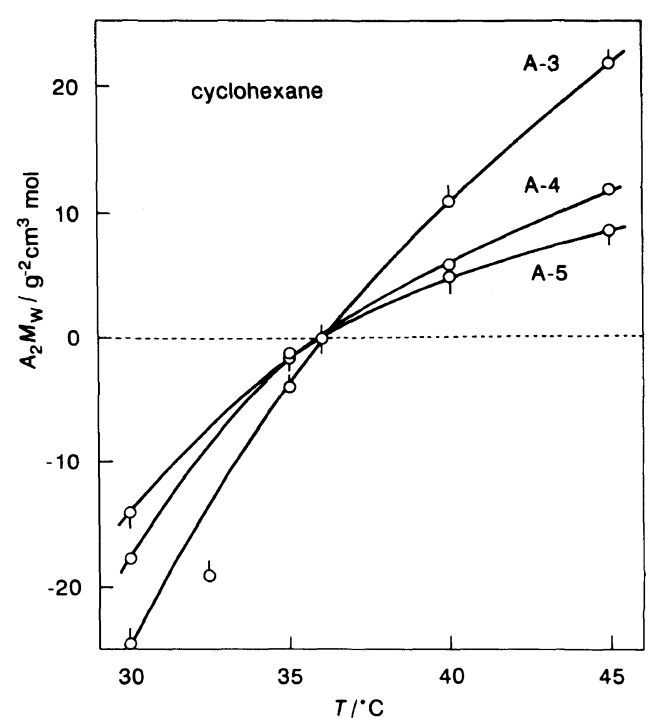

Figure 3. Temperature dependences of $A_{2} M_{w}$ for three samples in cyclohexane.

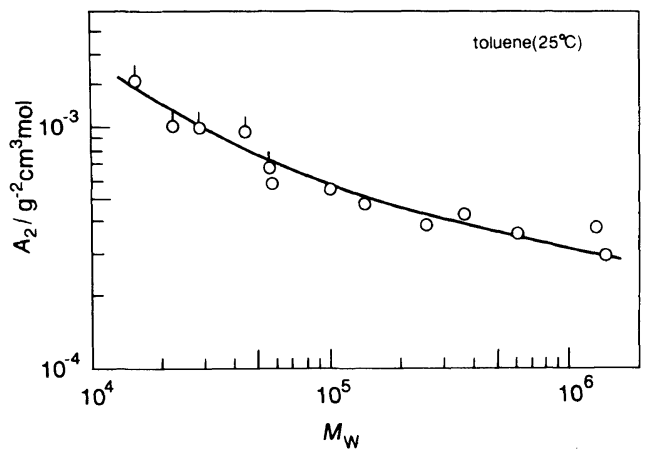

Figure 4. Double-logarithmic plot of $A_{2} v s . M_{w}$ for PPP in toluene at $25^{\circ} \mathrm{C}$. 
Table I. Results from light scattering and sedimentation equilibrium measurements on PPP samples in cyclohexane $\left(36^{\circ} \mathrm{C}\right)$ and toluene $\left(25^{\circ} \mathrm{C}\right)$

\begin{tabular}{|c|c|c|c|c|c|c|c|c|}
\hline \multirow{3}{*}{ Sample } & \multicolumn{3}{|c|}{ Cyclohexane $\left(36^{\circ} \mathrm{C}\right)$} & \multicolumn{5}{|c|}{ Toluene $\left(25^{\circ} \mathrm{C}\right)$} \\
\hline & \multirow{2}{*}{$M_{w} / 10^{4}$} & \multirow{2}{*}{$\frac{\left\langle S^{2}\right\rangle_{z}^{1 / 2}}{n m}$} & \multirow{2}{*}{$\delta / 10^{-3}$} & \multirow{2}{*}{$\frac{M_{w}}{10^{4}}$} & \multirow{2}{*}{$\frac{A_{2}}{10^{-4} \mathrm{~cm}^{3} \mathrm{~g}^{-2} \mathrm{~mol}}$} & \multirow{2}{*}{$\frac{\left\langle S^{2}\right\rangle_{z}^{1 / 2}}{\mathrm{~nm}}$} & \multirow{2}{*}{$\delta / 10^{-3}$} & \multirow{2}{*}{$M_{z} / M_{w}$} \\
\hline & & & & & & & & \\
\hline \multicolumn{9}{|c|}{ (light scattering at $546 \mathrm{~nm}$ ) } \\
\hline A-1 & 145 & 64.4 & & 145 & 2.91 & 69.4 & & \\
\hline A-2 & 126 & 58.3 & & 132 & 3.78 & 67.8 & & \\
\hline A-3 & 61.5 & 40.7 & & 61.3 & 3.58 & 44.5 & & \\
\hline A-4 & 35.0 & 29.6 & & 37.2 & 4.31 & 31.7 & & \\
\hline A-5 & 24.3 & 26.5 & & 25.8 & 3.84 & 27.2 & & \\
\hline A-6 & 14.4 & 19.6 & & 14.0 & 4.77 & 20.8 & & \\
\hline \multicolumn{9}{|c|}{ (light scattering at $436 \mathrm{~nm}$ ) } \\
\hline A-6 & 14.2 & 19.2 & 0.87 & 14.2 & 4.82 & 20.3 & 1.1 & \\
\hline A-7 & 9.58 & 16.4 & 1.4 & 10.0 & 5.46 & 16.7 & 1.6 & \\
\hline A-8 & 5.47 & 12.3 & 1.9 & 5.70 & 6.05 & 11.7 & 2.8 & \\
\hline \multicolumn{9}{|c|}{ (sedimentation equilibrium) } \\
\hline A-8 & & & & 5.59 & 6.75 & & & 1.06 \\
\hline A-9 & & & & 4.39 & 9.50 & & & 1.08 \\
\hline A-10 & & & & 2.82 & 9.88 & & & 1.06 \\
\hline A-11 & & & & 2.21 & 10.0 & & & 1.09 \\
\hline A-12 & & & & 1.55 & 15.7 & & & 1.06 \\
\hline
\end{tabular}

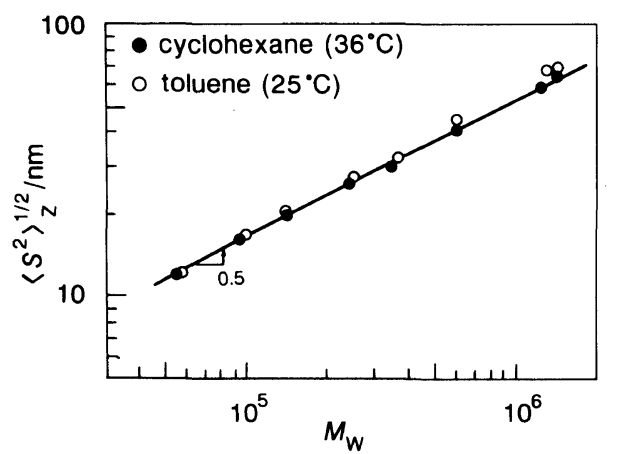

Figure 5. Molecular weight dependence of $\left\langle S^{2}\right\rangle_{z}^{1 / 2}$ for PPP in cyclohexane and toluene.

This indicates that PPP is brought to the theta condition in cyclohexane at $36^{\circ} \mathrm{C}$, where both inter- and intramolecular excluded-volume effects vanish.* On the, other hand, as shown in Figure $4, A_{2}$ in toluene is positive and decreases gradually with increasing molecular weight as usually found for flexible polymers in good solvents.

Figure 5 shows double-logarithmic plots of $\left\langle S^{2}\right\rangle_{z}^{1 / 2}$ vs. $M_{w}$ in cyclohexane at $36^{\circ} \mathrm{C}$ and in toluene at $25^{\circ} \mathrm{C}$. The data points in cyclohexane follow closely the straight line of a slope 0.5 indicated. Those in toluene follow this line up to an $M_{w}$ of about $3 \times 10^{5}$ and then deviate slightly upward from it. Thus the PPP chain in toluene is essentially unperturbed below $M_{w}$ $3 \times 10^{5}$ and perturbed above it by intramolecular excluded-volume effects; note that $A_{2}$ is positive in toluene.

Figure 6 shows double-logarithmic plots of

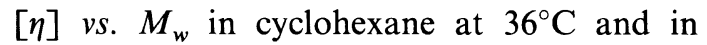
toluene at $25^{\circ} \mathrm{C}$. The data points in cyclohexane follow closely the smooth curve drawn, whose slope decreases from 0.8 to 0.55 with increasing $M_{w}$ in the $M_{w}$ range examined. This behavior, along with the square-root dependence of

* For fraction A-8, however, $A_{2}$ at $36^{\circ} \mathrm{C}$ remained positive (about $5 \times 10^{-5} \mathrm{~cm}^{3} \mathrm{~g}^{-2} \mathrm{~mol}$ ). This finding is similar to what has recently observed by Huber and Stockmayer ${ }^{16}$ and Konishi et al. ${ }^{17}$ for low-molecular weight polystyrene samples in cyclohexane, a theta solvent. 


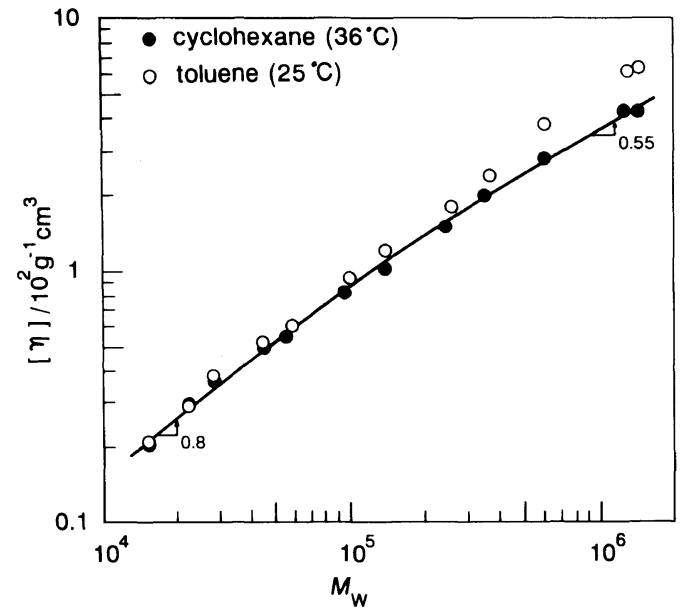

Figure 6. Molecular weight dependence of $[\eta]$ for PPP in the two solvents.

Table II. Results from viscosity measurements on PPP samples in cyclohexane $\left(36^{\circ} \mathrm{C}\right)$ and toluene $\left(25^{\circ} \mathrm{C}\right)$

\begin{tabular}{|c|c|c|c|c|}
\hline \multirow{3}{*}{ Sample } & \multicolumn{2}{|c|}{ Cyclohexane $\left(36^{\circ} \mathrm{C}\right)$} & \multicolumn{2}{|c|}{ Toluene $\left(25^{\circ} \mathrm{C}\right)$} \\
\hline & {$[\eta]$} & \multirow{2}{*}{$k^{\prime}$} & {$[\eta]$} & \\
\hline & $10^{2} \mathrm{~cm}^{3} \mathrm{~g}^{-1}$ & & $10^{2} \mathrm{~cm}^{3} \mathrm{~g}^{-1}$ & \\
\hline A-1 & 4.21 & 0.66 & 6.32 & 0.42 \\
\hline A-2 & 4.13 & 0.71 & 6.24 & 0.42 \\
\hline A-3 & 2.81 & 0.62 & 3.82 & 0.41 \\
\hline A-4 & 1.98 & 0.52 & 2.40 & 0.42 \\
\hline A-5 & 1.40 & 0.56 & 1.81 & 0.38 \\
\hline A-6 & 1.02 & 0.55 & 1.20 & 0.35 \\
\hline A-7 & 0.828 & 0.52 & 0.938 & 0.38 \\
\hline A-8 & 0.546 & 0.71 & 0.604 & 0.41 \\
\hline A-9 & 0.510 & 0.51 & 0.526 & 0.42 \\
\hline A- 10 & 0.371 & 0.57 & 0.384 & 0.40 \\
\hline A-11 & 0.297 & 0.58 & 0.287 & 0.44 \\
\hline A-12 & 0.207 & 0.73 & 0.210 & 0.40 \\
\hline
\end{tabular}

$\left\langle S^{2}\right\rangle_{z}^{1 / 2}$ in Figure 5, indicates that PPP in cyclohexane at $36^{\circ} \mathrm{C}$ is a semiflexible polymer in the unperturbed state. On the other hand, the data points in toluene appear slightly above the solid curve at $M_{w}$ lower than $3 \times 10^{5}$ but deviate definitely upward above this $M_{w}$. This upswing is due to intramolecular excludedvolume effects as found for $\left\langle S^{2}\right\rangle_{z}$. The numerical data for $[\eta]$ and Huggins' constant $k^{\prime}$ obtained are summarized in Table II.

\section{DISCUSSION}

\section{Wormlike Chain Parameters}

PPP in cylohexane at $36^{\circ} \mathrm{C}$ may be modeled by the wormlike cylinder, ${ }^{18}$ which is characterized by three parameters: the contour length $L$, persistence length $q$, and diameter $d$ of the cylinder. The mean-square radius of gyration $\left\langle S^{2}\right\rangle$ of this model chain at the limit of large $L / 2 q$ is written ${ }^{14}$

$$
\left\langle S^{2}\right\rangle=(1 / 3) q L-q^{2}
$$

where $L=M / M_{L}$, with $M$ and $M_{L}$ being the molecular weight and the molar mass per unit contour length, respectively. Yamakawa, Fujii, and Yoshizaki ${ }^{19,20}$ have derived an expression for $[\eta]$ of the model, which contains $M_{L}, q$, and $d$ as the parameters, that is,

$$
[\eta]=\left(2 q / M_{L}\right)^{3 / 2} M^{1 / 2} \Phi\left(d / 2 q, M / 2 q M_{L}\right)
$$

where $\Phi$ is given as a function of $d / 2 q$ and $L / 2 q$. A graphical procedure for analyzing experimental data based on this equation is also given. ${ }^{19,20}$ Later Bohdanecký ${ }^{21}$ and Bushin et $a l .{ }^{22}$ independently proposed a simple procedure for data analysis using the following approximation to eq 2 :

$$
\left(M^{2} /[\eta]\right)^{1 / 3}=A+B M^{1 / 2}
$$

with

$$
\begin{gathered}
A=A_{0} M_{L} \Phi_{\infty}^{-1 / 3} \\
B=B_{0}\left(2 q / M_{L}\right)^{-1 / 2} \Phi_{\infty}^{-1 / 3}
\end{gathered}
$$

where $\Phi_{\infty}$ is the Flory viscosity factor for unperturbed random coils and $A_{0}$ and $B_{0}$ are given as functions of $d / 2 q$. We examine whether these theoretical predictions are compatible with the present data for PPP in cyclohexane and allow the stiffness parameter $q$ to be evaluated.

The linear dependence of $\left\langle S^{2}\right\rangle_{z}^{1 / 2}$ on $M_{w}^{1 / 2}$ found in Figure 5 shows that the second term in eq 1 is negligible, yielding $\left\langle S^{2}\right\rangle_{z}=$ $(1 / 3) q\left(M_{w} / M_{L}\right)\left(M_{z} / M_{w}\right)$. The straight line in Figure 5 along with $M_{z} / M_{w}=1.07$ (the mean value from the sedimentation equilibrium) 


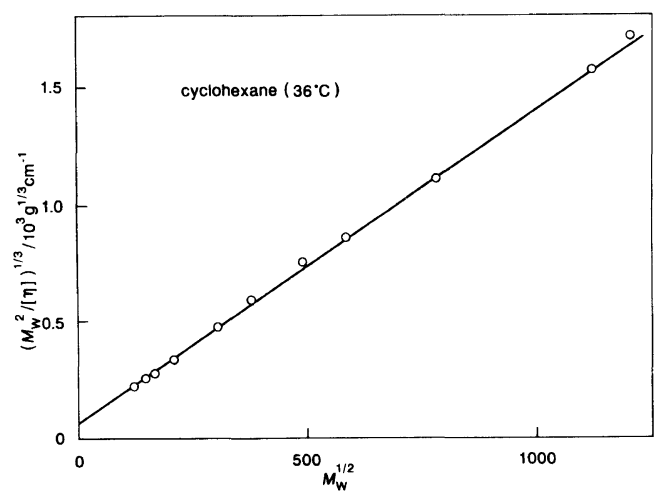

Figure 7. Plot of $\left(M_{w}^{2} /[\eta]\right)^{1 / 3}$ vs. $M_{\mathrm{w}}^{1 / 2}$ for PPP in cyclohexane at $36^{\circ} \mathrm{C}$.

gives $q / M_{L}=7.91 \times 10^{-3} \mathrm{~nm}^{2}$.

Figure 7 displays the $[\eta]$ data in cyclohexane at $36^{\circ} \mathrm{C}$ according to eq 3 . The data points follow closely the straight line indicated, yielding $A=51 \mathrm{~g}^{1 / 3} \mathrm{~cm}^{-1}$ and $B=1.32 \mathrm{~g}^{1 / 3}$ $\mathrm{cm}^{-1}$. It is noted that this analysis of light scattering and viscosity data has given two relationships among the three parameters involved and does not allow separate estimates of them. Since $[\eta]$ is rather insensitive to $d$, we may use an approximate value of $d$. From the molecular model of PPP chain constructed on the basis of the crystallographic data for polyacetylenes, ${ }^{23,24} d$ was estimated to be $1.1 \pm$ $0.2 \mathrm{~nm}$. This $d$ value along with the above $q / M_{L}$, $A$, and $B$ values yields the result: $M_{L}=480$ $\mathrm{nm}{ }^{-1}, q=3.8 \mathrm{~nm}$ and $\Phi_{\infty}=2.17 \times 10^{23} \mathrm{~mol}^{-1}$. The solid curve in Figure 8 represents the values calculated from the Yamakawa-FujiiYoshizaki theory with these parameter values, which fits the data points well. The uncertainty in $d$ of $\pm 0.2 \mathrm{~nm}$ gives rise to those in $M_{L}$ of $\pm 20 \mathrm{~nm}^{-1}$ and in $q$ of $\pm 0.1 \mathrm{~nm}$.

As mentioned above, at $M_{w}$ lower than $3 \times 10^{5}$ PPP in toluene is also in the unperturbed state. Therefore a similar analysis was performed with the $\left\langle S^{2}\right\rangle_{z}$ and $[\eta]$ data in toluene in this molecular weight range. The result is: $M_{L}=490 \mathrm{~nm}^{-1}, q=3.9 \mathrm{~nm}$, and $\Phi_{\infty}=2.35 \times 10^{23} \mathrm{~mol}^{-1}$. The solid line in Figure 5 and the dashed line in Figure 8

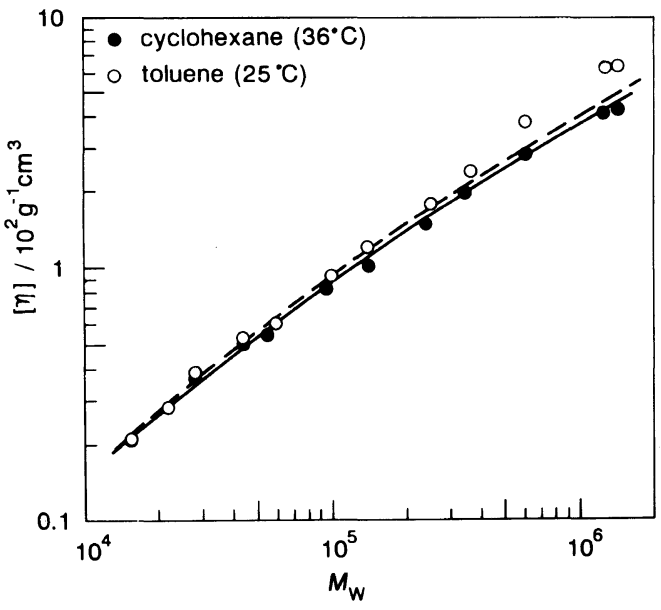

Figure 8. Comparison of the measured $[\eta]$ with the theoretical values calculated from the Yamakawa-FujiiYoshizaki theory: solid curve, calculated with $q=3.8 \mathrm{~nm}$, $M_{L}=480 \mathrm{~nm}^{-1}$, and $d=1.1 \mathrm{~nm}$; dashed curve, with $q=3.9 \mathrm{~nm}, M_{L}=490 \mathrm{~nm}^{-1}$, and $d=1.1 \mathrm{~nm}$.

Table III. Molecular parameters of poly(1-phenyl-1propyne)

\begin{tabular}{|c|c|c|c|c|c|}
\hline \multirow{2}{*}{ Solvent } & $q$ & $M_{L}$ & $d$ & \multirow{2}{*}{$\varepsilon$} & $\Phi_{\infty}$ \\
\hline & $\mathrm{nm}$ & $\mathrm{nm}^{-1}$ & $\mathrm{~nm}$ & & $10^{23} \mathrm{~mol}^{-1}$ \\
\hline Cyclohexane & $3.8 \pm 0.1$ & $480 \pm 30$ & $1.1^{\mathrm{a}}$ & 2.1 & 2.17 \\
\hline Toluene & $3.9 \pm 0.1$ & $490 \pm 30$ & $1.1^{\mathrm{a}}$ & 2.4 & 2.35 \\
\hline
\end{tabular}

\section{a Assumed values.}

represent the theoretical values with these parameter values. The agreement between theory and experiment is also satisfactory for $M_{w}$ below $3 \times 10^{5}$. The upward deviation of the data points at higher $M_{w}$ is ascribed to the intramolecular excluded-volume effect. The wormlike chain parameters of PPP thus determined are summarized in Table III. The $M_{L}$ values obtained are consistent with the structure of PPP whose $M_{L}$ is $480-530 \mathrm{~nm}^{-1}$ when estimated from the above-mentioned crystallographic data for polyacetylenes. ${ }^{23,24}$

In terms of $q$, PPP is much more flexible than typical semiflexible polymers such as poly $\left(p\right.$-benzamide) $(q=50 \mathrm{~nm})^{25}$ and poly(hexyl isocyanate) $(q=21-42 \mathrm{~nm})^{8-11}$ and 


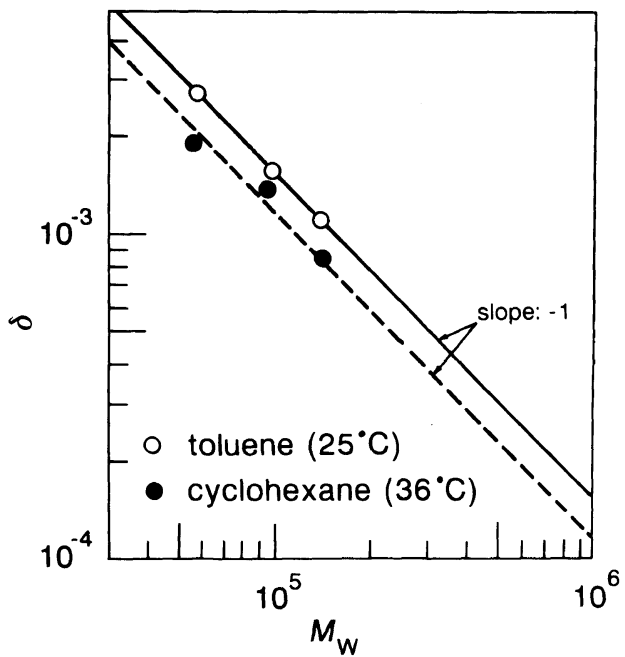

Figure 9. Double-logarithmic plot of $\delta$ against $M_{w}$ for PPP in cyclohexane and toluene.

comparable to polyamides containing piperazine rings on the main chain $(q=1.2-6.4$ $\mathrm{nm}){ }^{4-6}$ However it is definitely stiffer than polystyrene. ${ }^{17}$ It is noted in Table III that $\Phi_{\infty}$ is not a universal constant but depends slightly on solvent. The difference in $\Phi_{\infty}$ is a direct reflection of the finding that while the radii of gyration in the two solvents are essentially the same for $M_{w}$ below $3 \times 10^{5}$, the intrinsic viscosities are different. The $\Phi_{\infty}$ values in these solvents are lower than any of the theoretical values so far calculated, ${ }^{26-29}$ but are comparable to those for polyamides. ${ }^{4,5}$

Nagai $^{15}$ was the first present a theory for the optical anisotropy factor of a wormlike chain with cylindrical symmetry. For relatively flexible wormlike chains, his expression can be written

$$
\delta=\left(2 \varepsilon^{2} q M_{L} / 135 M\right)\left[1-0\left(q M_{L} / M\right)\right]
$$

where $\varepsilon$ is defined by

$$
\varepsilon=3\left(\alpha_{1}-\alpha_{2}\right) /\left(\alpha_{1}+2 \alpha_{2}\right)
$$

with $\alpha_{1}$ and $\alpha_{2}$ being respectively the longitudinal and transverse polarizabilities per unit contour length of the chain. The values of $\delta$ in the two solvents are plotted against $M_{w}$

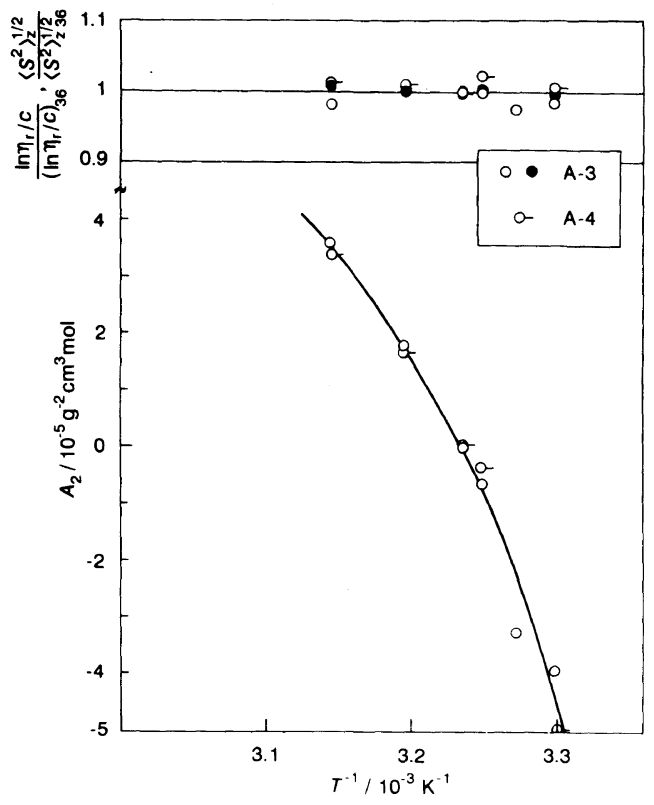

Figure 10. Temperature dependences of $A_{2},\left(\ln \eta_{\mathrm{r}}\right) / c$, and $\left\langle S^{2}\right\rangle_{z}^{1 / 2}$ in cyclohexane: $\left(\bigcirc, \bigcirc^{-}\right),\left\langle S^{2}\right\rangle_{z}^{1 / 2} ;(\bigcirc),\left(\ln \eta_{\mathrm{r}}\right) / c$. The subscript 36 indicates the quantities at $36^{\circ} \mathrm{C}$.

in Figure 9, which reproduces the inverse proportionality predicted by the leading term of eq 6 with reasonable accuracy; we note that the $\mathrm{O}\left(q M_{L} / M\right)$ term in eq 6 does not exceed 0.012 in the $M_{w}$ range studied. The values of $|\varepsilon|$ are estimated to be 2.1 and 2.4 for cyclohexane and toluene, respectively. These values are compared with 2.1 obtained by Sakurai et al. ${ }^{13}$ for poly(terephthalamide-pbenzohydrazide) in dimethylsulfoxide.

\section{Inter- and Intramolecular Excluded-Volume Effects}

Figure 10 shows the temperature dependence of $A_{2}$ for fractions A-3 and A-4 in cyclohexane in comparison with those of $\left\langle S^{2}\right\rangle_{z}$ and $\left(\ln \eta_{\mathrm{r}}\right) / c$. While $A_{2}$ changes remarkably with temperature, both $\left\langle S^{2}\right\rangle_{z}$ and $\left(\ln \eta_{\mathrm{r}}\right) / c$ virtually remain unchanged. Thus for PPP in cyclohexane, the intermolecular excluded volume changes remarkably with temperature, but the intramolecular excluded volume is essentially negligible. This is a typical feature of a 
semiflexible polymer, ${ }^{12}$ which reflects the fact that even though each segment has a finite excluded volume, it has no chance to meet with other segments on the same chain because of the stiff nature of the chain. Cellulose diacetate in 2-butanone ${ }^{30}$ and poly(phenylsilsesquioxane) in ethylene dichloride ${ }^{31}$ are known to exhibit similar behavior. In spite of the similarity in structure and solvent, PPP is contrasted with polystyrene, for which both effects are closely correlated. In toluene PPP undergoes both the inter- and intramolecular excluded-volume effects; the latter effect becomes appreciable at $M_{w} \sim 3 \times 10^{5}$, but is not so detailed as to permit quantitative analysis.

Acknowledgments. This work was financially supported by a Grant-in-Aid for Scientific Research from the Ministry of Education, Science and Culture of Japan.

\section{REFERENCES}

1. T. Masuda and T. Higashimura, Acc. Chem. Res., 17, 51 (1984).

2. T. Masuda and T. Higashimura, Adv. Polym. Sci., 81, 121 (1987).

3. T. Masuda, T. Takahashi, and T. Higashimura, Macromolecules, 18, 311 (1985).

4. M. Motowoka, T. Norisuye, and H. Fujita, Polym. J., 9, 613 (1977).

5. M. Motowoka, H. Fujita, and T. Norisuye, Polym. J., 3, 331 (1978).

6. J. Sadanobu, T. Norisuye, and H. Fujita, Polym. J., 13, 75 (1981).

7. T. Kitagawa, J. Sadanobu, and T. Norisuye, Macromolecules, 23, 602 (1990).

8. H. Murakami, T. Norisuye, and H. Fujita, Macromolecules, 13, 345 (1980).
9. M. Kuwata, H. Murakami, T. Norisuye, and H. Fujita, Macromolecules, 17, 2731 (1984).

10. T. Itou, H. Chikiri, A. Teramoto, and S. M. Aharoni, Polym. J., 20, 143 (1988).

11. S. Takada, T. Itou, H. Chikiri, Y. Einaga, and A. Teramoto, Macromolecules, 22, 973 (1989).

12. T. Norisuye and H. Fujita, Polym. J., 14, 143 (1982).

13. K. Sakurai, K. Ochi, T. Norisuye, and H. Fujita, Polym. J., 16, 559 (1984).

14. H. Yamakawa, "Modern Theory of Polymer Solutions," Harper and Row, New York, 1971, Chapter 5.

15. K. Nagai, Polym. J., 3, 67 (1972).

16. K. Huber and W. H. Stockmayer, Macromolecules, 20, 1400 (1987).

17. T. Konishi, T. Yoshizaki, T. Saito, Y. Einaga, and H. Yamakawa, Macromolecules, 23, 290 (1990).

18. H. Yamakawa and M. Fujii, Macromolecules, 6, 407 (1973).

19. H. Yamakawa and M. Fujii, Macromolecules, 7, 128 (1974).

20. H. Yamakawa and T. Yoshizaki, Macromolecules, 13, 633 (1980).

21. M. Bohdanecký, Macromolecules, 16, 1483 (1983).

22. S. C. Bushin, V. N. Tsvetkov, E. B. Lysenko, and V. N. Emelyanov, Vysokomol. Soedin. Ser. A, 23, 2494 (1981).

23. K. Shimamura, F. E. Karasz, J. A. Hirsch, and J. C. W. Chien, Macromol. Chem. Rapid. Commun., 2, 473 (1981).

24. J. C. W. Chien, F. E. Karasz, and K. Shimamura, Macromolecules, 15, 1012 (1982).

25. M. Arpin and C. Strazielle, Polymer, 18, 591 (1977).

26. J. G. Kirkwood and J. Riseman, J. Chem. Phys., 16, 565 (1948).

27. H. Yamakawa, "Modern Theory of Polymer Solutions," Harper and Row, New York, 1971. Chapter 6.

28. B. H. Zimm, Macromolecules, 13, 592 (1980).

29. J. G. de la Torre, A. Jimenez, and J. J. Frerre, Macromolecules, 15, 148 (1982).

30. H. Suzuki, Y. Muraoka, M. Saitou, and K. Kamide, Eur. Polym. J., 18, 831 (1982).

31. T. E. Helminiak and G. C. Berry, J. Polym. Sci. Polym. Symp., 65, 107 (1978). 